\title{
Gümüşhane İlinin Somut Olmayan Kültürel Miras Değerlerinin Sürdürülebilir Turizm Çerçevesinde İncelenmesine Yönelik Nitel Bir Araştırma
}

\section{A Qualitative Study on Investigation of Intangible Cultural Heritage Values of Gümüsshane Province within the Framework of Sustainable Tourism}

\begin{abstract}
İsmail ÇALIK ${ }^{*}$ Murat ÖDEMIŞ**

Öz: Sürdürülebilir turizm kavramı, yerel kültürün korunması ve gelecek nesillere aktarılmasında stratejik bir öneme sahiptir. Yerel kültürün özgün niteliklerini bünyesinde barındıran ve yaşayan hafızasını oluşturan somut olmayan kültürel miras unsurları ise, sürdürülebilir turizm bağlamında tartışılması gereken bir konudur. Bu noktada bu çalışmanın amacı, halen özgün niteliklerini korumayı başaran Gümüşhane'nin somut olmayan kültürel miras unsurlarının sürdürülebilir turizm bağlamında incelenmesidir. Çalışmada amaçlı örneklem yöntemlerinden kartopu örneklem yöntemine göre katılımcılar belirlenmiştir. Bu kapsamda çalışmanın örneklemini 16 paydaş katılımcı oluşturmuştur. Söz konusu katılımcılara yarı yapılandırılmış görüşme soruları yöneltilmiş olup, elde edilen sonuçlar betimsel analiz yöntemiyle analiz edilmiştir. Araştırmanın sonuçlarına göre, Gümüşhane'de çok sayıda unutulmaya yüz tutmuş somut olmayan kültürel mirasın bulunduğu, turizmin Gümüşhane’ye özgü somut olmayan kültürel mirasın korunmasında stratejik bir araç olabileceği ve turizm kapsamında değerlendirilmesi mümkün olan somut olmayan kültürel miras unsurları arasında en çok el sanatlarının ön plana çıktığı belirlenmiştir.
\end{abstract}

Anahtar sözcükler: Gümüşhane, Somut Olmayan Kültürel Miras, Sürdürülebilir Turizm, Yerel Kültür

\begin{abstract}
The concept of sustainable tourism has a strategic significance in preserving local cultures and passing them on to future generations. Those intangible cultural heritage elements that embody the unique qualities of the local culture and comprise the living memory form a subject that needs to be discussed within the context of sustainable tourism. From this perspective, the aim of this study is to examine elements of the intangible cultural heritage of Gümüşhane, which still maintain its original characteristics and qualities within the context of sustainable tourism. 16 stakeholder participants comprise the studied sample. From the purposeful sampling methods in this study participants were determined according to the snowball sampling method. Semi-structured interview questions were addressed to the participants and the results were analyzed by means of descriptive analysis. It is determined that there are many intangible cultural heritages begin to be forgotten in Gumushane, tourism may be a strategic tool in the preservation of the intangible cultural heritage of Gumushane and the handicrafts are the most important among the intangible cultural heritage elements that can be evaluated within the scope of tourism.
\end{abstract}

Keywords: Gümüşhane, Intangible Cultural Heritage, Sustainable Tourism, Local Culture

\footnotetext{
* Dr. Öğr. Ü. Gümüşhane Üniversitesi, Turizm Fakültesi, Turizm İşletmeciliği Bölümü, Gümüşhane. ismailcalik29@gmail.com

** ̈ğr. Gör. Gümüşhane Üniversitesi, Turizm Fakültesi, Turizm işletmeciliği Bölümü, Gümüşhane. mrodemis@gmail.com
} 


\section{Giriş}

Teknolojik gelişmelerin ve globalleşmenin etkisiyle ülkeler arasındaki keskin sınırların hemen hemen ortadan kalkmış olması, kültürel etkileşimi artırmıştır. Bu etkileşimin, farklı kültürler arasındaki önyargıları ortadan kaldırma potansiyeli bulunmakla beraber, olumsuz anlamda saf yerel kültürün baskın kültürün etkisi altında kalarak kültürel kimliğini kaybetme riskini de artırdığı söylenebilir. Turizm ise son dönemlerde kültürler arası etkileşimin şiddetini artıran, önemli bir globalleşme aracına dönüşmüş durumdadır. Bu nedenle turizm faaliyetlerinin doğru bir şekilde planlanmaması ve devamında iyi yönetilememesi, yerel kültür üzerinde yıkıcı etkilere yol açabilmektedir. Günümüzde hemen hemen her alanda etkisini hissettirmeye başlayan sürdürülebilirlik kavramı, bu nedenlerden dolayı turizmde de oldukça popüler bir kavrama dönüşmeye başlamıştır.

Diğer taraftan yerel kültürün yok olmasında, tek başına turizmi sorumlu tutmak doğru olmayacaktır. Özellikle teknolojik gelişmeler, insan yaşamını kolaylaştıran popüler kültürel unsurları hayatımıza sokarak yerel kültürel unsurların zamanla terk edilmesine yol açmaktadır. $\mathrm{Bu}$ etkenlerden dolayı, değişim ve gelişmelerin önüne geçmek ve yerel kültürel unsurları korumak ve gelecek nesillere aktarmak giderek zorlaşmaktadır. Çünkü insanlar çoğunlukla artık zor yaşam koşullarının bir ürünü olan eski yerel kültürel unsurları değil, hayatını nispeten kolaylaştıran popüler kültürel unsurları tercih etmeye başlamıştır. Bilhassa yerel kültüre ait somut olmayan kültürel mirasın büyük bölümü ancak bu kültürel ögeleri devam ettirme bilincine sahip insanlar yoluyla nesilden nesile aktarılabileceğinden en büyük olumsuz etkinin; somut olmayan kültürel miras kapsamında yer alan gelenek ve görenekler, örf ve âdetler, toplumsal bilgi birikimleri gibi toplumsal hafıza üzerinde gerçekleştiği söylenebilir.

$\mathrm{Bu}$ noktada turizmin, diğer birçok faktöre göre çok daha masum olduğunu söylemek yanlış olmayacaktır. Günümüzde kitle turizminin yerel kültür üzerindeki olumsuz etkilerinin giderilmesine ve koruma/kullanma dengesi gözetilerek hareket edilmesine yönelik olarak; sürdürülebilir turizmin, yerel topluma kültürel kimliğini koruma bilinci kazandırmak, kültürler arası olumlu etkileşimi artırmak, atıl durumdaki kültürel kaynakları turizm yoluyla koruyarak kullanmak ve yabancı kültürlerin yerel kültüre saygılı olmasını sağlamak gibi misyonları üstlenmiş olduğu görülmektedir. Bu suretle sürdürülebilir turizm kavramının, yerel kaynakların korunması ve bu kaynakların yerel anlamda ekonomik, sosyo-kültürel bir değere dönüştürülmesi noktasında destinasyonlar açısından stratejik bir konuma sahip olduğu söylenebilir.

Bu kapsamda, araştırmanın amacı Gümüşhane ilinde unutulan veya unutulmaya yüz tutmuş olan somut olmayan kültürel miras unsurlarının belirlenmesi, turizmin bu değerlerin korunmasındaki rolünün açıklanması ve turizmin kültürel değerler üzerindeki oluşturduğu tahribatın azaltılmasına yönelik önerilerde bulunulmasıdır.

\section{Kavramsal Çerçeve ve İlgili Araştırmalar}

\section{Somut Olmayan Kültürel Miras ve Sürdürülebilir Turizm}

1973 'ten 2003 yılına kadar uzunca bir süre tartışılmış bir kavram olan "somut olmayan kültürel miras" kavramı, sözleşme metnini oluşturan uzmanlar ve UNESCO'ya üye ülkeler arasında UNESCO'nun 32. Genel Konferansı'nın 17 Ekim 2003 tarihinde gerçekleştirilen oturumunda kabul edilmiştir. 2003 yılına kadar "somut olmayan kültürel miras" kavramını ifade etmek için "folklor" terimi üzerinde yoğunlaşan uzmanlar ve üye ülkeler, 2003 yılında "folklor" teriminden daha fazla miras unsurunu ifade eden "somut olmayan kültürel miras" kavramı üzerinde uzlaşmışlardır (Oğuz 2013). 
Somut olmayan kültürel miras kapsamında; ağızdan ağıza aktarılan gelenek ve âdetler, sanatsal etkinlikler, sosyal uygulamalar ve etkinlikler, festivaller, evren ve doğa ile ilgili bilgiler ve uygulamalar ya da geleneksel sanata ilişkin bilgiler ve uygulamalar yer almaktadır (UNESCO 2015). Kuşaktan kuşağa yayılan bu miras, toplulukların ve grupların geçmişiyle olan etkileşimleri doğrultusunda, sürekli olarak yeniden oluşturulmaktadır. Ayrıca bu miras, topluluk ya da gruplara kimlik ve devamlılık duygusu kazandırarak kültürel çeşitliliğe ve insan yaratıc1lığına duyulan saygıya da katkıda bulunmuş olur (KTB 2018).

Somut olmayan kültürel miras; topluluklara, gruplara ve bireylere bir kültürün devamı ve bir kültüre ait olma hissini vermekte ve onların dünyayı anlamalarını sağlayarak dünyaya ve yaşamlarına bir anlam yüklemelerine yardımcı olmaktadır. Ayrıca mevcut somut olmayan kültürel miras, kültürel çeşitliliğe 1şık tutmakta ve insanlığın günümüze kadar gelen yaratıcı potansiyelini ortaya koymaktadır. UNESCO, mevcut kültürel miras unsurlarının yaşatılması ve nesilden nesile aktarılması anlamında dünya çapındaki tanıtımlarını sürdürmekte ve bu anlamda farklı ülkelerle uluslararası işbirliğine yönelmektedir (UNESCO 2007).

Türkiye, 2003 y1lında UNESCO tarafından kabul edilen somut olmayan kültürel mirasın korunmasına ilişkin sözleşmeyi 19.01.2006 tarihli ve 5448 sayılı kanunla kabul ederek taraf olmuştur (Resmi Gazete 2006). Türkiye'nin "Dünya Somut Olmayan Kültürel Miras Listesi"ne (SOKÜM'e) giren 16's1 temsili 1'i ise acil koruma gerektiren 17 adet somut olmayan kültürel miras unsuru bulunmaktadır. Bunlar; Meddahlık Geleneği (2008), Mevlevi Sema Töreni (2008), Nevruz (İlk kez 6 ülkenin ortak dosyasıyla 2009 yılında kabul edilmiş olup, 2016 yılında ise 5 ülkenin daha katılımıyla genişletilmiştir.), Karagöz (2009), Aşıklık Geleneği (2009), Geleneksel Sohbet Toplantıları (2010), Alevi-Bektaşi Ritüeli Semah (2010), Kırkpınar Yağlı Güreş Festivali (2010), Geleneksel Tören Keşkeği (2011), Mesir Macunu Festivali (2012), Türk Kahvesi Kültürü ve Geleneği (2013), Ebru: Türk Kağıt Süsleme Sanatı (2014), İnce Ekmek Yapımı ve Paylaşımı Geleneği (4 ülke ile birlikte ortak dosya) (2016), Geleneksel Çini Sanatı (2016), Islık Dili (acil koruma gerektiren) (2017), Bahar Bayramı Hidırellez (Makedonya ile ortak dosya) (2017) ve Dede Korkut-Korkut Ata Mirası: Kültürü, Efsaneleri ve Müziğidir (Azerbaycan ve Kazakistan ile Ortak Dosya) (2018) (UNESCO 2018).

Sürdürülebilirlik ilkeleri turizmin ekonomik, sosyo-kültürel ve çevresel yönlerini ifade ederken, uzun vadede turizmde sürdürülebilirliği sağlamak için bu üç boyut arasında uygun bir denge kurulması gerekmektedir. Sürdürülebilir turizmin sosyo-kültürel ilkesi çerçevesinde; ev sahibi toplulukların sosyo-kültürel özgünlüğüne saygı gösterilmesi, yaşayan kültürel mirasın ve geleneksel değerlerin korunması ve kültürler arası anlayışa ve hoşgörüye katkıda bulunulması vurgulanmaktadır (UNEP \& UNWTO 2005, 11).

$\mathrm{Bu}$ suretle ev sahibi toplulukların yaşayan kültürel mirası ve geleneksel değerleri arasında yer alan somut olmayan kültürel miras unsurları ise; sürdürülebilir turizmin sosyo-kültürel göstergeleri kapsamında tartışılması gereken bir konudur. Böylece, dünyanın ortak mirası niteliğine sahip yaşayan bu değerlerin korunması ve gelecek nesillere aktarılmasında turizmin rolünün belirlenmesi sağlanabilir.

Yerel kültüre ait somut olmayan kültürel miras unsurlarının kontrolsüz bir şekilde turizme açılması, yerel kültürün sahip olduğu kültürel değerlerin yozlaşmasına ve zamanla yok olmasına sebep olabilir. Bu noktada sürdürülebilir turizm gelişimi, ekonomik ve çevresel unsurların yanı sıra, sosyo-kültürel varlıkların koruma/kullanma dengesi gözetilerek turizme kazandırılmasını amaçlamaktadır. Ayrıca, kaynakların korunması ve kontrollü bir şekilde turistlerin kullanımına sunulması bölgelere sürdürülebilir rekabet avantajı açısından fayda sağlayacaktır. 
Literatürde son dönemlerde, genel olarak kültürel miras kavramının ve kültürel miras kapsamında yer alan somut olmayan kültürel miras unsurlarının turizm kapsamında ya da turizm kapsamı dışında incelendiği çok sayıda çalışma bulunmaktadır. Bu kapsamda gerçekleştirilen bazı çalışmaların bir özetinin sunulması ise, konunun yazarlar tarafından ne derece önemsendiğinin ve hangi açılardan ele alındığının görülmesi açısından önemlidir. Bu doğrultuda literatürdeki bazı çalışmalar kısaca değerlendirildiğinde; öncelikle Yurttaş'ın (2008) çalışmasında, Gümüşhane ilinin Kürtün ilçesine ait kilise, köprü ve çeşmeden oluşan kültür varlıklarının, 2007 yılında yapılmış olan yüzey araştırmasında tespit edildiği ve söz konusu varlıkların varlığını belgeleyen çizim, fotoğraflama ve bilgilendirme notlarının verildiği görülmektedir. Günlü, Pırnar \& Yağcı'nın (2009) yapmış oldukları çalışmada, İzmir'de kültürel miras turizmi ile bölgesel gelişme arasında ilişki olup olmadığ 1 belirlenmeye çalışılmış ve yapılan araştırmada söz konusu faktörler arasında ilişkinin mümkün olduğu tespit edilmiştir. Bu noktada ise çalışmada; İzmir'de beklenen gelişmenin sağlanabilmesi için, kamu ve özel sektör arasında işbirliğinin ve destekleyici politikaların benimsenmesinin gerekliliğine dikkat çekilmektedir. Türker \& Çelik'in 2012 yılında yapmış oldukları çalışmada ise somut olmayan kültürel miras unsurlarının turistik ürün olarak mevcut kullanımı araştırılmış ve alternatif ürün geliştirme örnekleri sunulmuştur. Ayvacı \& Gülcan'ın (2017) çalışmalarında ise, ulusal somut olmayan kültürel miras (SOKÜM) unsurlarının turizm animasyon ürünleri başlığ 1 taşıyan araştırmalarda ne derece incelendiği belirlenmeye çalış1lmıştır. Ayvacı \& Gülcan (2017) bu kapsamda literatür incelemesi gerçekleştirmiş ve animasyon araştırmalarında ulusal somut olmayan kültürel mirasın yeteri kadar yer almadığını tespit etmişlerdir.

Ayrıca Chai'nin (2011) çalışmasında; UNESCO tarafından Kültür Mirası Şehri olarak kabul edilmiş olan Penang şehrinin geleceğe dair yapılanma sürecinde ve kentsel dönüşümünde, kültürel miras turizminin rolü tartışılmakta ve Penang'ın kültürel miras varlığ 1 analiz edilmektedir. Çalışmada, Penang'ın yapılanma sürecinde ve kentsel dönüşümünde kültür turizminin önemli araçlardan birisi olduğu vurgulanmaktadır. Bununla birlikte çalışmada; Penang'ın kültürel mirasının korunması ile ilgili olarak hırsızlık, tarihî binalarının korunması ve miras alanlarının gelişimini kontrol etmek için mevzuatın yetersizliği, tarihî binaların onarımı ve bakımı için tasarım kurallarının eksikliği gibi bir dizi sorunun varlığından bahsedilmektedir. Sonuçta, Penang’taki tarihî binaların korunmasında gelecek nesillere eğitim verilmesinin kültürel miras turizminin geleceğinin güvence altına alınmasında önemli bir role sahip olacağı vurgulanmaktadır. Alberti \& Guisti'nin (2012) İtalya Modena çevresindeki Motor Vadisi kümesi ile ilgili gerçekleştirdiği örnek olay çalışmasında, bir bölgenin gelişimine katkıda bulunan ve rekabet gücünü artıran bölgeye ait somut ve somut olmayan kültürel mirasın ve dolayısıyla turizmin gelişim düzeyi incelenmiştir. Bu kapsamda çalışmada, söz konusu bölgede yer alan motor sporları sektöründeki bölgesel kimlik ve miras; motor sektöründeki büyük firmaların, zanaatkarların, turizm organizasyonlarının, spor tesislerinin, kurumların, somut ve somut olmayan kültürel miras unsurlarının da içerisinde yer aldığı, turizm akışı ve rekabetçilik mekanizması içerisinde birbirine bağlı olarak işleyecek olan yeni bir kümelenme modeli olarak sunulmuştur.

Mitsche et al. (2013) ise çalışmalarında Hollanda, İtalya ve Almanya’ya ait somut ve somut olmayan kültürel miras unsurlarını koruma altına almak ve tanıtabilmek amacıyla geliştirmiş oldukları yorumlayıcı stratejilerden yararlanarak söz konusu ülkelerin kültürel miras unsurlarını belirlemişlerdir. Çalışmada bu ülkelerde bulunan Amsterdam, Leipzig ve Genoa kentleri yorumlayıcı strateji için seçilmiştir. Bu doğrultuda örneğin Amsterdam kentinin; yorumlayıc1 strateji çerçevesinde müzeleri başta olmak üzere kanalları, kırmızı ışık bölgesi, mimarisi, tarihî binaları gibi somut kültürel miras unsurları ile kültürü, atmosferi, özgürlügü gibi somut olmayan unsurlarının bir bütünlük oluşturduğu, ayrıca kentin daha çok somut niteliklerinin açık hava 
müzesi görüntüsü vererek ziyaretçilere yeni ve eğlenceli deneyimler sunduğu belirtilmiştir. Omar (2013) tez çalışmasında Malezya'ya ait kültürel mirasın sürdürülebilirliğinin sağlanmasında, planlama ve etkin yönetimin önemine dikkat çekmektedir. Çalışmada Omar (2013), sosyal ve kültürel unsurları dikkate alan bir sürdürülebilir kültürel miras turizm modeli önermektedir. Durovic \& Lovrentjev (2014) yaptıkları çalışmada bir bölgenin finansal, sosyal ve çevresel boyutta sürdürülebilir gelişim kaydedebilmesi anlamında, turizmin ve turizm kapsamında yer alan kültürel turizmin sürdürülebilir gelişiminin önemine dikkat çekmektedir. Söz konusu çalışmada, kültürel turizmin sürdürülebilir gelişimine yönelik olarak bazı göstergeler önerilmektedir.

Bir başka çalışmada Ott, Dagnino \& Pozzi (2015) somut olmayan kültürel miras alanında yenilikçi eğitim müdahalelerinin nasıl tasarlanacağını tartışmaktadır. Bu anlamda çalışmada, yenilikçi teknolojik ürünler arasında yer alan "teknolojik anlamda öğrenme teknikleri”nin somut olmayan kültürel mirasın korunmasında nasıl verimli bir şekilde kullanılacağına dair önerilerde bulunulmaktadır. Severo \& Venturini (2016) yaptıkları çalışmada ulusal eğilim ve özelliklerini belirlemek üzere, 2003 UNESCO sözleşmesinin uygulandığı ulusal ağları (Fransa, İtalya ve İsviçre ülkelerini) karşılaştırmışlar ve bu ulusal ağların somut olmayan kültürel miras unsurları bağlantılarını tanımlamak üzere yeni bir metodoloji (web haritalama) ve yeni bir temsil biçimi (1sı haritası) önermişlerdir. Cozzani et al. (2017) yenilikçi teknolojiler arasında yer alan iTreasures uygulamasının somut olmayan kültürel mirasın korunması ve eğitiminde rol oynayıp oynamayacağını ve bu rolün ne derece etkili olabileceğini araştırmışlardır. Sonuç olarak çalışmada; i-Treasures uygulamasının öğretim ve öğrenme süreçlerini olumlu yönde destekleyerek somut olmayan kültürel mirasın korunmasına ve gelecek nesillere aktarılmasına yardımcı olduğu sonucuna varılmıştır. Bu nedenle çalışmada; i-Treasures uygulamasının unutulmaya yüz tutmuş olan somut olmayan kültürel miras unsurlarının korunması ve gelecek nesillere aktarılması anlamında organizasyonlar, okullar ve kurumlar tarafindan benimsenmesi gereken faydalı bir araç olduğu vurgulanmıştır.

Celi \& Moore (2015) ise Avrupa'nın sahip olduğu zengin somut olmayan kültürel mirasın korunarak, gençlere istihdam oluşturabilmesine yönelik uygulanabilir firsatları ve yatırımcılar için kamu-özel sektör ortaklığı firsatlarını bir projeyle ortaya koymaya çalışmışlardır. Esfehani \& Albrecht (2016) yaptıkları çalışmada somut olmayan kültürel miras ile turizm arasındaki etkileşimi incelemişlerdir. Bu kapsamda İran'ın güneyinde yer alan Qeshm Parkı'ndaki etnografik alan çalışmalarının sonuçları incelenmektedir. Esfehani \& Albrecht'e (2016) göre somut olmayan kültürel miras, turizmde üç farklı yolla ortaya çıkmaktadır. Birincisi, turizme yönelik cazibenin artırılması ve turizme katkı kaynağı olarak; ikincisi, koruma aracı olarak, özellikle doğal çevrenin yerel topluluk için güçlü kültürel anlamlara sahip olduğu durumlarda; üçüncü olarak ise ziyaretçilerin kültüre ve doğaya yönelik hassasiyetlerini artırmak için bir yol gösterici olarak ortaya çıkmaktadır. Lopez-Guzman \& Santa-Cruz (2017) somut olmayan kültürel miras ile İspanya Cordoba'daki Patios Festivali ve turizm gelişimi arasındaki ilişkiyi belirlemeye çalışmışlardır. Bu doğrultuda bu değişkenlerin söz konusu destinasyonu ziyaret eden ziyaretçilerin memnuniyetleri üzerindeki katkısı ortaya konulmaya çalışılmıştır. Çalışmanın amacı doğrultusunda; ziyaretçilerin cinsiyet, yaş, eğitim düzeyi ve gelir gibi sosyo-demografik özellikleriyle memnuniyetleri arasında istatistiksel olarak anlamlı bir farklılık olup olmadığı belirlenmeye çalışılmıştır. Çalışmada cinsiyet değişkeni değerlendirildiğinde erkekler ve kadınlar arasında memnuniyet düzeyleri bakımından istatistiksel olarak anlamlı bir farklılık tespit edilmesine rağmen; yaş, eğitim düzeyi veya gelir değişkenleri ile ilişkili anlamlı bir farklılık tespit edilmemiştir. Bununla birlikte çalışmada; faktör analizi sonucunda "konfor", "hizmet" ve "adapte olabilirlik" adıyla üç farklı faktör belirlenmiştir. 


\section{Gümüşhane'de Kültürel Miras ve Turizm}

Karadeniz Bölgesi'nin Doğu Karadeniz Bölümü’nde yer alan Gümüşhane ili; doğusunda Bayburt, batısında Giresun, kuzeyinde Trabzon ve güneyinde ise Erzincan illeri ile komşudur. İlin güneyinde Şiran, Kelkit ve Köse ilçeleri; kuzey kesiminde ise Gümüşhane Merkez, Torul ve Kürtün İlçeleri bulunmaktadır (Gümüşhane Valiliği 2017). Genel olarak Gümüşhane ili kültürel özellikleriyle Karadeniz ve Doğu Anadolu bölgeleri arasında "kültürel geçiş bölgesi" özelliği göstermektedir (Gümüşhane Valiliği 1999, 132). Gümüşhane ili; "On binlerin Dönüş Yolu”, "Kral Yolu" ve "Ipek Yolu" gibi tarihî yollar üzerinde bulunması sebebiyle de, Doğu ve Kuzey Doğu Anadolu yol ağları arasında özel bir konuma sahiptir. Trabzon'u İran'a ve Azerbaycan'a bağlayan tarihî yollar üzerinde bulunan Gümüşhane, her dönemde bir geçit noktası olma özelliğini muhafaza etmiştir (Özkan \& Yurttaş 2012, 15). Bu nedenle Gümüşhane ve çevresi, tarihsel süreç içerisinde coğrafi özelliklerinden çok stratejik konumuyla ön plana çıkmıştır (Çiğdem \& Emir 2016, 28).

Gümüşhane yukarı dere ve aşağı dere olarak adlandırılan birbirinden farklı iki önemli coğrafi, kültürel ve tarihî sahaya sahiptir (Gümüşhane Valiliği 2016, 16). Yukarı dere olarak bilinen yerleşim alanlarında Doğu Anadolu kültürü hâkimken, aşağı dere bölümünde ise Doğu Karadeniz kültürü hâkimdir (Çiğdem 2008, 18). Ayrıca Gümüşhane'nin Kelkit ve Şiran ilçelerinde, kısmen İç Anadolu Bölgesi'nin etkisinin bulunduğu söylenebilir (Ülker et al. 2011, 15). Bu durum, ilin kültürel açıdan zenginlik kazanmasını sağlamıştır. Çalık et al. $(2013,107)$ köklü geçmişi ve ipek yolu üzerinde konumlanmış olmasının, Gümüşhane ilinde birbirinden farklı kültürel eserlerin görülmesini mümkün kıldığını belirtmektedirler. Tarihsel süreç içerisinde Türk, Rum ve Ermenilerin birlikte yaşadığı bölgede; günümüzde bu dönemlerden kalma ev, ibadethane, köprü, hamam vb. mekanlar bulunmaktadır. Bu kapsamda; Süleymaniye Mahallesi, Santa antik kenti, Krom Vadisi, Satala antik kenti kültürel miras turizmi açısından değerlendirilebilecek kültürel alanlar olarak dikkat çekmektedir.

Somut olmayan kültürel miras unsurları açısından değerlendirildiğinde ise zengin bir kültürel geçmişe sahip olan Gümüşhane'nin; el sanatları, yöresel mimari, gastronomi kültürü ve diğer halk kültürü unsurları açısından çeşitliliğe sahip olduğu söylenebilir. Gümüşhane'nin sahip olduğu bu çeşitlilik ve zenginlik, bir kültür mozaiğine dönüşmesini sağlamıştır. Bu durum, Gümüşhane'ye özgü değerlerin koruma/kullanma dengesi gözetilerek sürdürülebilir turizm yoluyla gelecek nesillere ulaştırılmasının gerekliliğini ortaya koymaktadır.

Literatür incelendiğinde; Gümüşhane'nin sahip olduğu somut olmayan kültürel miras unsurlarını tüm yönleriyle ele alan en kapsamlı çalışmanın, Ülker et al. (2011) tarafından yapıldığ görülmektedir. Ülker et al. (2011) yapmış oldukları bu çalışmada, Gümüşhane merkezine ve ilçelerine ait halk kültür ögeleri arasında yer alan ve sürdürülebilir turizm çalışmaları açısından ön plana çıkabilecek bazı konulara yer vermişlerdir. Bu kapsamda çalışmada; Gümüşhane'ye özgü mimari yapı, halk oyunları, halk mutfăğ, tarihî yapılar, evlenme inanç ve uygulamaları ve kaybolan kültürel değerler gibi konulara değinilmiştir.

\section{Araştırmanın Yöntemi}

\section{Araştırmanın Evreni ve Örneklemi}

Çalışmanın evrenini Gümüşhane ilinin somut olmayan kültürel miras unsurları hakkında bilgi sahibi olan eğitimci, yazar, kanaat önderi, halk eğitim merkezi yöneticisi ve el sanatı ustası vb. paydaşlar oluşturmaktadır. Araştırmanın örnekleminin belirlenmesi sürecinde ise konunun amacına uygun kişilerle görüşülmesine özen gösterilmiş̧ir. Örneklemin belirlenmesi sürecinde ilk aşamada kapsamlı bir literatür taraması yapılarak, Gümüşhane ilinin kültürel özellikleri ile ilgili 
araştırma yapan eğitimci ve yazarlar belirlenmiştir. Sonraki aşamada Gümüşhane ilindeki Halk Eğitim Merkezi yöneticilerinden ilde unutulmuş veya unutulmaya yüz tutmuş el sanatlarının neler olduğu ile ilgili görüş alınmıştır. Bu görüşler neticesinde Halk Eğitim Merkezi yöneticilerinin ve el sanatı ustalarının da örnekleme dahil edilmesine karar verilmiştir. Ayrıca, görüşmeye karar verilen paydaşların önerileri doğrultusunda araştırmanın amacına uygun ve Gümüşhane kültürüne vâkıf kişiler de örnekleme eklenmiştir. Bu kapsamda çalışmanın örneklemini 16 paydaş oluşturmuştur. Katılımcıların mesleği ve bilgi alınan temel konular ise Tablo 1 'de yer almaktadir;

Tablo 1. Katılımcılara İlişkin Bilgiler

\begin{tabular}{|c|c|c|}
\hline & Mesleği & Bilgi Alınan Temel Konular \\
\hline K 1 & Eğitimci/Yazar & $\begin{array}{l}\text { Guduculuk (Çömlekçilik), Gümüşhane Konakları, Gümüşhane } \\
\text { Düğün Gelenekleri }\end{array}$ \\
\hline K 2 & Gazeteci & Yayla Kültürü, Yöresel Mimari \\
\hline K 3 & Halk Eğitim Merkezi Müdürü & Düğün Gelenekleri, Zilli Kilim ve Kelkit Kültürü \\
\hline K 4 & Eğitimci/Yazar & Düğün Gelenekleri, Kültürel Ögeler, Festivaller \\
\hline K 5 & Eğitimci/Yazar & Kültürel Ögeler, Göç Yolları, El Sanatları, Konaklar \\
\hline K 6 & Tarihçi & Göç Yolları, Gümüşhane Tarihi \\
\hline K 7 & Eğitimci & Yayla Kültürü, Düğün Gelenekleri, Festival ve Şenlikler \\
\hline K 8 & Kanaat Önderi/ Gazeteci & Kız İsteme Ritüelleri, Yöresel Mimari, Yayla Kültürü \\
\hline K 9 & El Sanatı Ustas1 & Ahşap İşlemeciliği, İpek Halı Dokumacıllı̆ı \\
\hline K 10 & El Sanat1 Ustas1 & İpek Halı Dokumacılığı, Ahşap İşlemeciliği \\
\hline K 11 & Halk Eğitim Merkezi Müdürü & Gümüşhane'de El Sanatları \\
\hline K 12 & El Sanatı Ustas1 & Demircilik \\
\hline K 13 & Eğitimci & Kültürel Ögeler, Taş İşlemeciliği, Düğün Gelenekleri \\
\hline K 14 & El Sanatı Ustası & Guduculuk (Çömlekçilik) \\
\hline K 15 & Kanaat Önderi & Taş Evler ve Yöresel Mimari \\
\hline K 16 & Eğitimci/Yazar & Yöresel Mimari \\
\hline
\end{tabular}

Çalışmanın örneklem belirleme sürecinde ise amaçlı örneklem belirleme yöntemleri arasında gösterilen kartopu örnekleme yöntemi kullanılmıştır. Zincir örnekleme yöntemi olarak da bilinen kartopu örnekleme yönteminde detaylı bilgilerin sağlanması amaçlanmaktadır (Patton 1990, 176). Bu yöntemle, konu ile ilgili bilgi sahibi olan kişilerden referans alınması suretiyle örneklem genişletilerek nispeten araştırmaya faydalı olacak katılımcılar örnekleme dahil edilir (Baş \& Akturan 2013, 200).

\section{Veri Toplama Tekniği ve Aracı}

Çalışmada veri toplama tekniği olarak yarı yapılandırılmış görüşme tekniği kullanılmıştır. Veri toplama aracı olarak ise yarı yapılandırılmış görüşme formundan faydalanılmıştır. Nitel araştırmalarda görüşme tekniğinin kullanılmasının nedeni, görüşülen kişilerin bakış açılarını net bir biçimde ortaya koymaktır. Ayrıca nitel araştırmalarda yüzeysel değil, derinlemesine bilgi edinilmesi amaçlanır (Şencan 2005, 505; Cemaloğlu 2012, 152; Büyüköztürk et al. 2012, 150; Baş \& Akturan 2013, 111). Yarı yapılandırılmış görüşmeler ise katılımcıların etkinliğini hedefleyerek, bireysel olarak anlam ve deneyimlerin ifade edilmesine olanak sağlar (King \& Horrocks 2010, 16). Yarı yapılandırılmış görüşmede sorular esnektir ve her katılımcıdan spesifik veriler toplanır. Diğer taraftan daha önceden belirlenen ifade ve soru ayrıntılarına yer verilmeyerek genel bilgiler elde edilmeye çalış1ır (Merriam 2015, 87).

Araştırmada kullanılan yarı yapılandırılmış görüşme formu; UNESCO'nun (2015) somut olmayan kültürel miras unsurlarına yönelik olarak belirlemiş olduğu gelenek ve âdetler, çeşitli sanat etkinlikleri, sosyal uygulamalar ve etkinlikler, festivaller, geleneksel mimari, el sanatları 
kategorilerinden esinlenilerek yeniden geliştirilmiştir. Soru formunda araştırmanın amacına uygun 10 açık uçlu soru yer almaktadır. Açık uçlu sorular genel olarak Gümüşhane ilindeki geleneksel el sanatları, yöresel mimari unsurları, festivaller, düğün gelenekleri, halk oyunları, yayla şenlikleri ve turizmin bu değerlerin korunmasındaki rolü ile ilgilidir.

Gümüşhane ve ilçelerindeki paydaşlarla yapılacak görüşmeler için randevu alınmış ve görüşme talebine olumlu yanıt veren 15 kişi ile yüz yüze, 1 kişi ile ise telefonla 17.06.201501.08.2015 tarihleri arasında görüşmeler gerçekleştirilmiştir. Görüşmeler, katılımcının onayı alınarak ses kayıt cihazı ile kayıt edilmiştir. Görüşme yapılan 16 katılımcı; K1 (Katılımcı 1), K2, K3......K16 şeklinde kodlanmıştır.

\section{Veri Analiz Yöntemi}

Elde edilen verilerin analiz edilmesinde betimsel analiz yöntemi kullanılmıştır. Betimsel analizde temel amaç elde edilen bilgileri sistematik ve açık bir biçimde okuyucuya sunmaktır. $\mathrm{Bu}$ analiz türünde veriler, ortaya koyulan temalara göre özetlenir ve yorumlanır. Veriler araştırma soruları ile ortaya çıkan temalara göre oluşturulabilir. Ayrıca veriler, gözlem ve görüşme süreçleri neticesinde yararlanılan sorular ya da boyutlar göz önüne alınarak da sunulabilir. Betimsel analizde görüşülen katılımcıların görüşlerini çarpıcı bir biçimde yansıtmak amacıyla doğrudan alıntılara yer verilebilir (Yıldırım \& Şimşek 2016, 240).

Veri toplama sürecinde elde edilen veriler ilk olarak deşifre edilmiştir. Deşifre sürecinin ardından metinler tematik kategorilere ayrılmıştır. Belirlenen kategoriler çalışmanın amacı, araştırmacının tutumu, bilgi birikimi ve katılımcıların her bir kategoriye ilişkin verdikleri yanıtlara göre şekillenmektedir (Merriam 2015, 175). Bu doğrultuda çalışmada; alt ve üst temaların neler olacağına katılımcıların cevaplarının bağlamı, araştırmacının gözlem ve birikimi ve Gümüşhane ilinin mevcut potansiyeline göre karar verilmiştir. Bu aşamada 3 üst tema ve 11 alt tema oluşturulmuştur. Tablo 2'de alt ve üst temalara ilişkin ayrıntılara yer verilmektedir.

Tablo 2. Verilerin Analizi Sonucu Ortaya Çıkan Üst Tema ve Alt Temalar

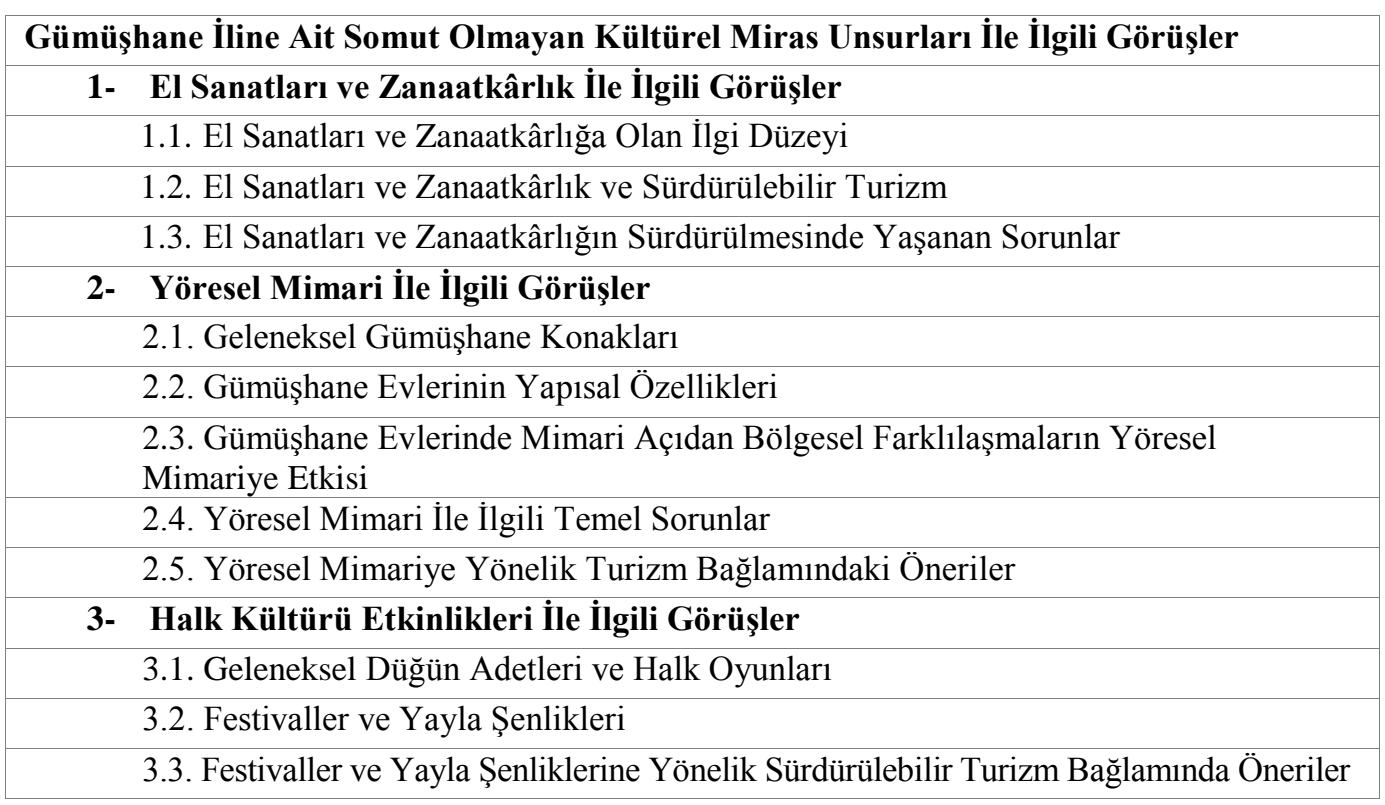

Yorumlama süreci, ham verinin ötesinde araştırmacının konuyla ilgili objektif ve bilimsel çıkarımlarda bulunmasını gerektirir. Bahsedilen konunun öneminin vurgulanması, verilerin anlamlandırılması, açıklamalar yapılması ve sonuç çıkarılması sürecin diğer unsurlarıdır (Patton 2014, 
480). Bu bağlamda çalışmanın analiz sürecinde ise, tematik kategorilerin oluşturulmasının ardından bulgular kısaca yorumlanmış ve bulgular kısmında ön plana çıkan katılımcı görüşleri doğrudan alıntı yapılarak aktarılmıştır.

\section{Bulgular}

\section{El Sanatları ve Zanaatkârlık İle İlgili Görüşler}

Mülakatlarda ilgili paydaşlara geçmişten günümüze il genelindeki el sanatlarının türleri, sürdürülebilir turizm bağlamında nasıl korunabileceği, üretim süreçleri, ekonomik anlamda nasıl değerlendirilebileceği bağlamında sorular iletilmiştir. Bu kapsamda, Gümüşhane ilinde geleneksel olarak yürütülen el sanatları unsurları arasında ön plana çıkanlar; gudu (çömlek) yapımı, zilli kilim, ala kilim, ipek halı dokumacılığı, demircilik, ahşap işlemeciliği, köstere taşı, sepetçilik olarak sayılabilir. Belirtilen el sanatlarının sürdürülmesinin önünde kentleşme, gençlerin ilgisizliği, paydaşlardan yeterli destek alınamaması, hammadde temininin güçlüğü gibi zorluklar bulunmaktadır. Konuyu bir el sanatı ustası şu şekilde açıklamaktadır:

“20-30 yıl önce Kürtün'de ahşap oymacıliğg gençlere ögretiliyordu ve gençler bu konuda istekliydi. Fakat son yıllarda artık gençler el sanatını ögrenmeye istekli değil. Ahşap oymacılığını daha çok emekli olan kişiler hobi amacıyla sürdürmektedir. Sadece bu el sanatından elde ettiği gelirle evini geçindiren oldukça az" (K9).

El sanatlarının günlük ihtiyaçlar için üretilen ürünler dışında turistlere yönelik hediyelik eşya olarak üretiminin gerçekleştirilmesi katılımcılar tarafından önerilmektedir.

"Fonksiyonel olarak kullanılan ürünler dışında turistlerin tercih edebileceği hediyelik eşyalar küçük objeler hâlinde tasarlanarak pazarlanabilir" (K5).

Sürdürülebilir turizmde kültürel ögelerin metalaştırılmaması için kontrollü bir gelişim önerilmektedir. Yani kısa vadeli ekonomik fayda yerine orta ve uzun vadeli ekonomik faydaya odaklanan, geleneksel üretim şekillerinin geliştirilmesi vurgulanmaktadır. Belirtilen konu katılımcılar tarafından şöyle ifade edilmiştir:

“Gümüşhane'de guduculuğun (çömlekçiliğin) seri üretiminin yapılması yerine geleneksel üretim şekillerinin sürdürülmesi daha doğru olabilir. Ayrıca gudu yapan kadınların el sanatın sürdürmede istekli olabilmeleri için eğitim, finansman, hedef pazar oluşturulması konularında desteklenmeleri gerekmektedir" (K1-K8).

Geleneksel el sanatlarının sürdürülmesinde yaşanan diğer zorluklar; hammaddenin elde edilmesinde bazı yasal güçlüklerin bulunması, iklim ve arazi koşullarına dayalı sorunlar olarak belirtilmiştir:

"Ahşap oymacılı̆̆ el sanatının pazarlanmasında değil de yasal olarak üretiminde problemler var. Ladin ăgacının kesilmesine yasal sinırlamalar getirilmektedir. Bu durum maalesef kayıt dışı üretimi teşvik ediyor" (K10).

"Gudu yapımında kullanılan toprak, köyün dışından sırtlarına sepetle yüklenerek getirilmektedir. Bu durum yaşlılar için fiziksel anlamda mümkün olmamaktadır. Gençler ise bu işin zorluğuna katlanmaya hevesli değildirler" (K14). 


\section{Yöresel Mimari İle İlgili Görüşler}

Gümüşhane iline özgü yöresel mimari değerlerinin mevcut durumu ve mimari unsurlarının sürdürülebilir turizm kapsamında nasıl korunacağ1 ve değerlendirileceği ile ilgili katılımcıların görüşleri alınmıştır. Gümüşhane konaklarının yapımının tarihsel süreci bir katılımcı tarafından şu şekilde ifade edilmiştir:

“Gümüşane'de özellikle cumhuriyetin kurulmasından sonra bölgenin zenginleri tarafindan konaklar yaptırılmıştır. Balyemez Konağı, Hasan Fehmi Ataç Konağı, Özdenoğlu Konăğ ve Ali Bey Konağ ilk konaklar arasındadır. Geleneksel Gümüşhane evleri, iki katlı ve bahçeli olarak tasarlanmıştır. Genel olarak, bu evlerin ana yapı malzemesini taş, kerpiç ve ahşap oluşturuken, damlarda sac, kiremit, toprak; bacalarda ise tuğla malzemesi kullanılmaktadır" (K1).

Gümüşhane evlerinin oluşumunda zengin tarihî geçmişi, topoğrafik özellikleri, iklim şartları, yapı malzemeleri ve yaşam biçiminin etkisi bulunmaktadır (Gümüşhane Valiliği 1999, 137).

“Gümüşhane'nin yukarı dere olarak adlandırlan Doğu Anadolu Bölgesi'ne yakin yerlerde geleneksel köy evleri genel olarak taş ve kerpiçten yapılan duvar, üzerine harâmı ve mertek denilen ağaçlar yerleştirilir ve arasına pir adı verilen selvi ăgacı dalları kaplanırdl. Daha sonra toprak ve saman karıştırılarak balçık hâline getirilir ve çatının üstüne dökülürdü. Belli bir süre sonra "loğ" adı verilen taşla toprak sağlamlaştırllır ve su geçişi için çatı kenarlarına meyil verilirdi" (K15).

Torul ve Kürtün ilçelerinde ise Karadeniz Bölgesi’ne yakınlığın etkisiyle yöresel mimaride farklılaşma olduğu söylenebilir. Bu durum katılımcılar tarafından şu şekilde ifade edilmiştir:

“Gümüşhane ilinin aşağı dere olarak adlandirılan Karadeniz Bölgesi’ne nispeten yakın yerleşim bölgelerinde ve Torul, Kürtün ilçelerinde ahşap evlerde geleneksel olarak "dolma (Doğu Karadeniz evlerinde ahşap karkas yapıda uygulanan bir tür duvar tekniği. Karşılıklı iki dikme arasında üst üste oturtmak suretiyle tahtayla duvar örülmesi)" ve "bağdadi (Ahşap karkas yapı sistemi. Özellikle Doğu Karadeniz evlerinde yaygın olarak görülür; duvarlarda dış yüzeylere sık sık çıtalar çakıp, üzerlerinin sıvanması; ahşap direkler üzerine çakılan çıta ve kamışların sıvanmasıyla yapılan duvar veya tavan; ya da burada kullanılan çatı)" adı verilen mimari usul yaygindır" (K16).

"Torul ve Kürtün ilçelerinde köy evlerinin yapımında "hartama" adı verilen ahşaptan örgü kullanilırdl. Hartama ilin mimari yapısında yer alan önemli bir kültür ögesiydi. Hartama, çatıya destek olan levha hâline getirilmiş tahta malzemedir. Hartama, Gümüşhane'nin Karadeniz Bölgesi'ne yakın ilçelerinde, ladin ă̆acının ince şeritler hâlinde kesilmesi ile yapılan çatı kaplama malzemesidir. Torul ilçesinde köy evlerinin yapımında taş kullanılırdı. Çatısı olan evlere küspey, çatısı olmayan evlere ise pey denilirdi. Evlerde bulunan tandir adl verilen firtnlarda ekmek vb. ürünler pişirilirdi. Taş evlerin özelliği kışın sıcak, yazın serin olmasıdır" (K1-K2).

Gümüşhane ilinin mimari yapısında plansızlık olduğu, bölgenin tarihsel süreç içerisinde mimari gelişimini sağlayamadığı ise konu ile ilgili belirtilen diğer bir görüştür: 
“Gümüşhane'de mimari açıdan plansızlık söz konusudur. Tarihsel süreç içerisinde ilin mimari gelişimi sağlanamad. Gümüşhane ileri gelenlerine ait olan konaklar yalnızca konaklama amacıyla değil, misafir ă̆ırlama amacıyla da kullanilırdı. Buradaki ilk konaklar, Ali Fuat Kadirbeyoğlu tarafindan kendisine ve dönemin Valisi'ne 1925 yılında yaptırılmıştır. Il genelindeki konakların nitelikli projeler aracılığılla, geleneksel yap korunarak restore edilmesi önerilebilir. Hasan Basri Güzeloğlu'nun Gümüşhane Valiliği esnasında bu konaklardan bazıları restore edilerek, yiyecek-içecek tesisi olarak kullanılmaya başlandı. Gümüşhane merkezde 40'a yakın geleneksel ev ve konak bulunmaktadır. Bu konakların her biri ayrı bir alanda hizmet verebilecek şekilde tasarlanabilir ve turistik çekicilik oluşturabilir" (K8).

Süleymaniye Mahallesi, Gümüşhane ilinin eski yerleşim yeridir. Süleymaniye Mahallesi; Türk, Rum ve Ermenilerin birlikte yaşadığı bir kültür mozaiğidir. Süleymaniye Ulu Camii, Bagios Ionnes Kaya Kilisesi, Rum Erkek Lisesi, Ulu Camii Haziresi, Süleymaniye Hamamı, Hacı Tahir Efendi Türbesi gibi tarihî ve kültürel varlıklar bulunmaktadır. Bu kültürel varlıkların korunması ve gelecek nesillere aktarılması açısından, bölgedeki altyapı ve restorasyon çalışmalarının ivedilikle sonlandırılması ve bu bölgenin açık hava müzesi şeklinde planlanarak ziyaretçilere açılması önerilebilir.

Köylerde bulunan eski taş ve ahşap evlerin restore edilerek turistlerin kullanımına sunulması, hem taş ev kültürünün yaşatılması hem de ekonomik gelir elde edilmesi açısından bölgeye katkıda bulunacaktır. İlde geleneksel mimarinin korunduğu köy evlerinin, Doğu Karadeniz Kalkınma Ajansı ve diğer fon kaynaklarının teşvikiyle projelendirilmesi gerekmektedir. İl genelinde konak, köy evi gibi yapıların korunması ve gelecek nesillere aktarılmasını sağlamak ve restorasyonunda kullanılmak üzere kamu kuruluşları tarafından ilgili yapının hissedarlarına teşvik de verilmektedir.

Krom Vadisi, İmera Köyü ve Santa Harabeleri başta olmak üzere farklı inanç gruplarına ait inanç merkezlerinin turizm yoluyla korunması sağlanabilir. Bu bölgelerde yer alan tarihî yapıların aslına uygun bir şekilde restore edilmesi önerilebilir. Tarihî binaların aslına uygun bir şekilde restore edilmesiyle Gümüşhane tarihinin izlerinin tamamen yok olması engellenecek, tarihî ve kültürel varlıkların otantik değeri korunmuş olacak ve bu somut değerlerin gelecek nesillere aktarılması sağlanacaktır. Günümüz turistik tüketicilerinin genel olarak beklentileri de, tarihe tanıklık etmiş olan tarihî ve kültürel varlıkların yapıldığı dönemin izlerini ve mistik havasını birebir yansıtacak şekilde restore edilerek korunması ve gelecek nesillere aktarılmasıdır. Bu nedenle aslına uygun bir şekilde restore edilmemiş tarihî yapıların turistik çekiciliğini yitirmesi de kaçınılmazdır. Diğer yandan, Gümüşhane yaylalarından geçen yeşil yol kapsamında planlanan alanların, özellikle tarihî yapıların yer aldığı bölgelerde belli bir mesafeye kadar araç girişinin engellenerek yürüyüş yolu olarak planlanması, bölgedeki tarihî yapıların tahribatının önlenmesi açısından faydalı olacaktır.

\section{Halk Kültürü Etkinlikleri ile İlgili Görüşler}

Gümüşhane ilinde diğer halk kültürü etkinlikleri, "halk oyunları", "kullanılan enstrümanlar", "dügü̈n gelenekleri", "festival vb. etkinlikler" kategorilerinde ele alınacaktır. Katılımc1ların bu kapsamda belirttikleri ilk konu ilde halk kültürü etkinliklerinin bölgeden bölgeye farklılık göstermesidir. Bu konuyu katılımcılar şu şekilde ifade etmektedir:

“Gümüşhane'nin Erzincan ve Bayburt'a yakın yörelerindeki düğ̈̈n âdet- 
leri, şiveleri, müzik enstrümanları, Giresun ve Trabzon'a yakın olan ilçelerden farklıdır. Bu temel farklılık, Doğu Anadolu ve Karadeniz Bölgesi kültür farklılıklarından kaynaklanmaktadır. Gümüşhane'nin Erzincan ve Bayburt illerine yakın köy ve ilçelerinde genel olarak davul-zurna müzik enstrümanı olarak kullanılırken, Trabzon-Giresun illerine yakın köy ve ilçelerde ise kemençe kullanılmaktadır. Merkeze bağlı bazı köy dügünlerinde, horon ve halay birlikte oynanmaktadır" (K1-K3).

Gümüşhane ilinin Bayburt-Erzincan illerine yakın bölgelerinde düğün gelenekleri farklı ritüeller içermektedir. Örneğin Kelkit ilçesinde, komşu köyler arasında düğ̈̈ne sesleme geleneği halen devam etmektedir. Bu gelenek bir katılımcı tarafından şu şekilde anlatılmaktadır:

"Kelkit ilçesinde akrabalık ilişkisi olmaksızın komşu köyü sakinleri dügünlere davet edilir. Davet edilen misafirler, köy konaklarında misafir edilir. Konak başı denilen kişiler, bu misafirlerin ihtiyaçlarını gidermekten sorumludurlar. Konakların işlerini hizmetliler görür; hizmetlerine karşllık olarak konak misafirlerinden toplanan ücret, konak başlarl vasitasiyla bu kişilere dağıtılır. Dügü̈n yemeği organizasyonunu "keyveni" ya da "hanımağa" denilen kadın ustalar idare eder, burada yapllan yemekler her bir konağa dă̆ıtılır. Konak misafirlerinin yemek dişındaki ihtiyaçları konak sahibi tarafindan karşılanır, bunun yanında misafirler, gerektiğinde konağın ihtiyaçları için kullanılmak üzere malzemeler getirirler. Ayrıca, düğünlerde "çeyiz yazma" geleneği sürmektedir. Bu geleneğe göre düğ̈̈n başlamadan önce çeyizler, takılardan başlamak üzere yazllarak (hesaplanarak) kayıt altına alınmaktadır. Bu işlemin yapılmasının nedeni, taraflar arasındaki ayrılık ihtimaline karşı, çeyiz tutarını belgelendirmektir. Dügü̈n misafirlerine yakınlı derecesine göre yün çorap ve havlu gibi hediyeler verilirdi" (K3).

Gümüşhane yöresinin kendine has kız isteme ritüeli bulunmaktadır. Bu geleneğin günümüzde unutulmaya yüz tuttuğu belirtilmelidir. Bu durum bir katılımc1 tarafından şu şekilde özetlenmiştir

"Öncelikle erkeğin ailesinden kadınlar öncülüğ̈̈nde, istenilecek kızı görmek için hamama gidilir, burada kı tarafinın ăgzı aranır. "İşittirme" de denilen bu gelenek Gümüşhane köylerinde halen sürdürülmektedir. Yani kızın ailesinin ilk tavrı ölçülür. Daha sonraki aşamada, olumlu bir geri-dönüş oldu ise kız evine istemeye gidilir. Kız tarafi ilk seferde kızı vermeye yanaşmaz, ama kızın görüşü de alınarak karşı tarafa açık kapı birakılır. Bu süreçte erkek ile ilgili araştırma yapılır. Sonraki aşamada, iki tarafin da ortak tanıdığı kişiler kız istemeye götürülürek erkek tarafina kefil olurlardı. Günümüzde ise çiftler tanıştıktan sonra ailelere haber veriliyor, bu aşamada ailelere çiftleri onaylamak kaliyor" (K8).

Gümüşhane ilinin merkeze bağlı aşağı dere olarak da adlandırılan köylerinde düğün geleneklerinde genel itibarıyla Karadeniz kültürünün etkisine rastlanır. Katılımcılardan bazıları bu durumu şu şekilde ifade etmişlerdir:

“Gümüşhane’nin, merkeze bağlı (aşağı dere) köylerinde yürüyüş kolonileri kurularak dügün alayı yola koyulurdu. Buradaki köylerde Rum nüfus yoğun olduğundan, düğ̈̈nlerdeki müzikler kemençe ağırlıklıydl. Düğün yolunda, kemençe eşliğinde yol havası söylenirdi. Dü̈̆ünlerde ve gelin 
alma esnasında "bıçak oyunu" vb. oyunlar oynanırdl. Fakat günümüzde köylerde yapılan geleneksel düğünler, yerini salon dügünlerine birakmıştır. Gümüşhane ilinde ve bazı ilçelerinde dügünlerde imece usulü dayanışma söz konusuydu. Örneğin, en fakir ailelerin dügünlerinde bile yardımlaşmayla çok çeşitli yemekler servis edilirdi. Gümüşhane Kürtün ilçesindeki düğ̈̈n adetlerinde damat gelin almaya gitmezdi. Gelin ve damadın iki sağdıcı olurdu. Yüksek bir yerden, çiflerin başına ceviz ve findık dökülmesi bölgeye özgü bir düğ̈̈n geleneğiydi. Kürtün ilçesinde farklı nedenlerden dolayı "kaçarak evlenme" durumu çok slk yaşanırdl. Bu durumun temel nedeni ekonomik etkenlerdir. Dügünlerde sağdıç veya damadın sırtına çıkılarak para istenirdi" (K4-K7).

Festivaller ve yayla şenlikleri geçmişte ve günümüzde ilin somut olmayan kültürel miras unsurları arasında önemli bir yer tutmaktadır. Festival ve şenliklerin özellikleri, sorunlar ve önemi hakkında katılımcılar şu konulara değinmişlerdir:

“Gümüşhane'nin merkeze bağll köy ve ilçelerinde; Herfene Geceleri, Mayıs 7'si, Ayazma Şenliği, Kafalak Şenliği, Aprul'un 5'i, Burgababa Şenliği gibi etkinlikler düzenlenirdi. Günümüzde bu kapsamda çok saylda yayla şenliği ve festival düzenlenmektedir. Bu şenliklerde farklı köylerden gelen kişiler oyunlar oynar ve dostluklar pekiştirilirdi. Gümüşhane il genelinde yaz aylarinda düzenlenen yayla şenlikleri ve festivaller, bölgeden göç eden gurbetçi vatandaşların memleket özlemlerini gideren, geleneksel kültürel paylaşımlarını artıran etkinliklerdir. Bu kültürün yaşatılması ve gelecek nesillere aktarllması açısından; yayla şenliklerinin amacına uygun şekilde sürdürülmesi ve yöreye ait somut olmayan kültürel miras unsurlarının yaşatılması önemlidir. Gümüşhane yaylarının bir çoğunu Trabzon, Giresun halkı kullanmaktadır. Yaylalara yönelik alt yapı ve üst yapı çalışmalarının çevresel ve sosyo-kültürel etkiler göz önünde bulundurularak tamamlanmast gerekmektedir" (K7-K4).

Gümüşhane merkezdeki köylerin bazılarında günümüzde artık yok olmuş olan "musalla” adı verilen pazarların yeniden canlandırılmasına ilişkin bir katılımoının önerisi şu şekildedir:

"Gümüşhane'nin bazı köylerinde "musalla" adı verilen yerlerde Pazarlar kurulurdu. Bu pazarlarda yöredeki köylerden getirilen ürünler satılırdl. Günümüzde yine bu bölgede organik ürünlerin satılacă̆ "organik ürünler pazarı" kurularak ziyaretçilerin kullanımına sunulabilir. Bu şekilde Gümüşhane Musalla vadisindeki belirlenecek bir alana organik ürünler pazarı kurulabilir" (K2).

\section{Sonuç ve Öneriler}

Sürdürülebilir turizm, planlanacak olan turizm etkinliklerinin ekonomik, sosyo-kültürel ve çevresel tahribatın boyutlarına özen gösterilmesine odaklanan bir turizm yaklaşımıdır. Sürdürülebilir turizmde yerel halkın turizm gelirlerinden daha adil pay alması; turizmin orta ve uzun vadede oluşturduğu sosyo-kültürel tahribatı engelleyecek politikaların desteklenmesi ve turizm gelişiminin çevresel taşıma kapasitesi dikkate alınarak planlanması temel öncelikler arasındadır. Chhabra'ya $(2010,21)$ göre geniş bir yelpazeye ve karmaşık bir yapıya sahip olan sürdürülebilir turizm, ev sahibi toplumun kültürel/doğal ortamlarının korunması ile bu kaynakların ticarileştirmesi arasında uygun bir denge kurulmasını amaçlamaktadır. Şanlı̈̈z-Özgen et al. $(2016,49)$ sürdürülebilirliğin doğal ve kültürel mirası içine alan bir kavram olduğunu belirtmektedir. Başka 
bir ifadeyle doğal ve kültürel miras, sürdürülebilir bir anlayış çerçevesinde yürütülen turizm hareketlerinin bir parçası durumundadır. Lane'e $(2009,30)$ göre sürdürülebilir turizm hedeflerinin başarılması, gerekli değişimlerin zaman alması nedeniyle uzun ve her paydaşın beklenti ve çıkarlarının farklılaşmasından dolayı ise oldukça tartışmalı ve sancılı bir süreçtir. Bu nedenle sürdürülebilir turizm sürecinin, söz konusu hassas dengeler gözetilerek dikkatli bir şekilde planlanması gerekmektedir. Gerektiği şekilde planlanması ve yönetilmesi gereken en önemli unsurlardan birisi ise, yerel halkın kültürel varlıklarıdır.

Ölçer-Özünel'e (2017) göre geleneksel kültür, doğayla uyumlu bir ilişki geliştirmiş olup çevreye genellikle saygılıdır. Geleneksel yaşam kültürünü hâlen devam ettirmeyi başaran insanlar, doğayı yaşamlarını idame ettirebilmek için korumaları gerektiğinin bilincindedir. Bu nedenle geleneksel bilgiyi ve kültürünü koruma bilincine sahip olan yerel halk, ahşap ve taş işlemeciliği gibi doğal ürünlere yönelerek doğanın da korunmasına katkıda bulunmaktadır. Bu noktada turizmin ise, doğayı koruma bilincinin oluşturulmasında ve bu bilincin devam ettirilmesinde etkili bir araç olarak değerlendirilebileceği söylenebilir.

Kültürel mirasın ekonomik potansiyelinin giderek farkına varmaya başlayan çok sayıda destinasyon, hizmet ekonomilerinin bir parçası olarak kültür turizmini geliştirmeye ve desteklemeye yönelmiş durumdadır (Timothy 2014). Ancak öngörülen turizm gelişimi sürecinde ekonomik yararlar getirecek girişimlerle birlikte, özellikle yerel halkın kültürel niteliklerini koruyup geliştirecek sürdürülebilir planlamaların da yapılması gerekmektedir. Çünkü turizm, sürdürülebilir ilkeler çerçevesinde planlanması ve yönetilmesi durumunda yerel kaynakların korunmasına ve gelecek nesillere aktarılmasına katkıda bulunabilecektir.

Bu noktada, geleneksel kültürel değerler arasında gösterilen somut olmayan kültürel miras unsurlarının unutulmaması ve popüler kültüre yenik düşmemesi önemlidir. Bunun yolu ise bu değerlerin koruma/kullanma dengesi gözetilerek sürdürülebilir turizm ilkeleri rehberliğinde ziyaretçilerin kullanımına sunulmasıdır. El sanatları, bölgeye özgü yöresel mimari unsurları, düğün gelenekleri, geleneksel festivaller ve şenlikler gibi somut olmayan kültürel miras unsurlarının sürdürülebilir turizm yoluyla ziyaretçilerin kullanımına sunulması; hem kırsal bölgelerin ekonomik kalkınmasına hem de bu değerlerin gelecek nesillere ulaştırılmasına katkı sağlayacaktır.

Gümüşhane; tarihî ipek yolu, on binlerin göç yolu, kral yolu gibi tarihî göç yollarının geçiş bölgesinde bulunması nedeniyle tarihsel dönemlerde stratejik öneme sahip bir merkez olmuştur. Kültürel geçiş bölgesinde konumlanmış olan Gümüşhane, Doğu Karadeniz ve Doğu Anadolu Bölgeleri'nin kültürel özelliklerine sahiptir. Tarihsel süreç içerisinde Türk, Rum ve Ermenilere ait birçok kültürel yapıtın yer aldığı Santa Antik Kenti, Krom Vadisi, Olucak Köyü ve Süleymaniye Mahallesi'nde bu kültürel çeşitliliğin izlerine rastlanmaktadır.

Gümüşhane'ye özgü el sanatları unsurları kapsamında; guduculuk (çömlekçilik), ahşap işlemeciliği, zil yapımı ve demircilik, taş işlemeciliği, zilli kilim, ala kilim ve ipek halı dokumacılığı ön plana çıkmaktadır. Diğer yandan Gümüşhane'ye adını vermesine rağmen, ilde gümüş işlemeciliğinde özgünlük yaratılamamıştır. Merkeze bağlı Dölek Köyü guduculuk el sanatında; Kürtün ilçesi ahşap işlemeciliği, zil yapımı ve ipek halı dokumacılığında; Şiran ilçesi taş işlemeciliği ve ala kilim dokumacıllğında; Kelkit ilçesi ise zilli kilim ve taş işlemeciliğinde gelişim gösterebilir. Belirtilen el sanatlarının turizm açısından değerlendirilmesinin yolu; yerel halkın projeler yoluyla ekonomik olarak desteklenmesi, gençlerin bu el sanatlarını yapmaya özendirilmesi ve el sanatlarında geleneksel yöntemlerin sürdürülmesidir.

Diğer taraftan Gümüşhane'nin yöresel mimari unsurları açısından zengin varlıklara sahip 
olduğu söylenebilir. Bu yapıların turizm işletmesi olarak kullanılacak olması ilin turizmine katk1 sağlayacaktır. Cumhuriyetin kurulmasından sonra ilde inşa edilen konaklar, yiyecek-içecek işletmeciliği açısından önemli bir işlev görmektedir. Özdenoğlu Konağı, Balyemez Konağı ve Ataç Konağı gibi yapılar günümüzde turizm işletmesi olarak kullanılsa da, bunun gibi yaklaşık 40'a yakın tarihî konak restore edilerek kullanıma açılmayı beklemektedir. Diğer taraftan bu konaklarda Gümüşhane'ye özgü ritüellerin canlandırılması, Gümüşhane yemeklerinin sunulması ve misafir memnuniyeti unsurlarına daha fazla önem verilmesi önerilebilir.

Süleymaniye Mahallesi (Eski Gümüşhane); ulaşılabilirliği, tarihî yapılarının niteliği ve çeşitliliği, farklı inanç gruplarına ait dini merkezlerinin bulunması ve otantiklik özelliği ile turizm açısından potansiyeli olan bir bölgedir. Süleymaniye Mahallesi'nin kentsel koruma planının kabul edilmesi ile birlikte restorasyon ve yenileme faaliyetlerinin hızlanacağı söylenebilir. Ermeni Metropolitan Kilisesi, Süleymaniye Camii, Ali Kadirbeyoğlu Konağı, Rum Okulu gibi tarihî yapılar bölgenin inanç ve kültür turizmi potansiyelini ortaya koymaktadır. Bu potansiyelin hayata geçirilebilmesi için planlanan yol ve diğer altyapı yatırımlarının tamamlanması, tarihî yapıların restorasyonunun bilimsel ölçütlere ve aslına uygun şekilde gerçekleştirilmesi ve tanıtım faaliyetlerine finansal destek sağlanması gerekmektedir.

Gümüşhane’ye özgü geleneksel düğün adetleri bazı köylerde sürdürülse de, kent merkezinde yapılan düğünlerde bu adetlerin birçoğuna artık rastlanmadığı söylenebilir. Düğüne sesleme, işittirme, çeyiz yazma, karşılama adı verilen bölgeye özgü farklı düğün gelenekleri bulunsa da günümüzde bu geleneklerin yoğun göç ve ekonomik gerekçelerle unutulmaya yüz tuttuğu belirtilmelidir. Düğüne sesleme, işittirme, çeyiz yazma, karşılama adı verilen bölgeye özgü farklı dügün gelenekleri bulunmaktadır.

Yayla festivalleri ve yayla kültürü, Gümüşhane açısından önemli bir kültürel ögedir. İlin Doğu Karadeniz Bölgesi'ne yakın olan Kürtün, Torul ilçelerinde ve merkeze bağlı bazı köylerde yaylacılık geleneği devam etmektedir. Yayla turizmi açısından bu geleneklerin sürdürülmesi ve çeşitlendirilmesi gerekmektedir.

Son olarak literatür incelemelerinde, Gümüşhane ile ilgili yapılmış olan kültürel miras çalışmalarının yetersiz olduğu belirlenmiştir. Bu nedenle gelecek çalışmalarda, Gümüşhane ve Türkiye'nin diğer illerine yönelik somut ve somut olmayan kültürel miras unsurlarının turizm bağlamında değerlendirildiği çalışmaların sayısının artırılması önerilebilir. Ayrıca ileride yapılacak sürdürülebilir turizm çalışmalarından elde edilecek sonuçların, bölgede sürdürülebilir bir gelişimin sağlanmasına yönelik olarak ilgili paydaşlara önemli kaynaklar sunacağı düşünülmektedir.

Yazarların Notu: Bu çalışma 12-15 Kasım 2015 tarihinde düzenlenen 16. Ulusal Turizm Kongresi'nde sunulan "Somut Olmayan Kültürel Miras Unsurlarının Sürdürülebilir Turizm Kapsaminda Değerlendirilmesi: Gümüşhane IIli Örneği” adlı bildirinin genişletilmiş ve güncellenmiş hâlidir. 


\section{KAYNAKÇA}

Akyüz E. (1995). "Geleneksel Konut Mimarisine İlişkin Kavramlar”. Ege Mimarlık Dergisi 3/17 (1995) 1-3. Kaynak: 〈http://egemimarlik.org/17/06.pdf>.

Alberti F. G. \& Guisti J. D. (2012). "Cultural Heritage, Tourism and Regional Competitiveness: The Motor Valley Cluster". City, Culture and Society 3/4 (2012) 261-273.

Ayvacı H. \& Gülcan B. (2017). "Türkiye'deki Turizm Animasyonlarında Somut Olmayan Kültürel Miras (SOKÜM) Ulusal Unsurlarına Bakış”. Journal of Recreational Tourism Research 4/1 (2017) 207-223.

Baş T. \& Akturan U. (2008). Nitel Araştırma Yöntemleri: Nvivo ile Nitel Veri Analizi, Örnekleme, Analiz, Yorum. Ankara 2008.

Büyüköztürk Ş., Çakmak E. K., Akgün Ö. E., Karadeniz Ş. \& Demirel F. (2012). Bilimsel Araştırma Yöntemleri. Ankara 2012.

Celi E. M. \& Moore R. E. (2015). "Safeguarding Intangible Cultural Heritage Through Youth Employment and Public/Private Partnership". 2015 Digital Heritage. Kaynak: <http://ieeexplore.ieee.org/abstract/ document/7419555/>.

Cemaloğlu N. (2012). "Veri Toplama Teknikleri”. Ed. A. Tanrıöğen, Bilimsel Araştırma Yöntemleri (2012). Ankara.

Chai L. T. (2011). "Culture Heritage Tourism Engineering at Penang: Complete the of "The Pearl of Orient"”. Systems Engineering Procedia 1 (2011) 358-364.

Chhabra D. (2010). Sustainable Marketing of Tourism Cultural and Heritage Tourism. Abingdon 2010.

Cozzani G., Pozzi F., Dagnino F. M., Katos A V. \& Katsouli E. F. (2017). "Innovative Technologies for Intangible Cultural Heritage Education Preservation: The Case of i-Treasures". Personel and Ubiquitous Computing 21/2 (2017) 253-265.

Çalık İ., Kaya F., Akdu U. Sezerel H., Aras G. \& Köstepen A. (2013). Gümüşhane İli Turizm Potansiyeli. Gümüşhane 2013.

Çiğdem S. \& Emir O. (2016). "Gümüşhane İlinin Prehistoriası ve İlkçağı Üzerine Genel Bir Değerlendirme”. Eds. B. Nazır \& K. Saylan, Gümüşhane Tarihi (2016). Gümüşhane.

Çiğdem S. (2008). Gümüşhane Bölgesi'nin Tarih ve Arkeoloji Araştırmalar. Gümüşhane 2008.

Durovic M. \& Lovrentjev S. (2014). "Indicators of Sustainability in Cultural Tourism". The Macrotheme Review 3/7 (2014) 180-189.

Esfehani M. H. \& Albrecht J. N. (2016). "Roles of Intangible Cultural Heritage in Tourism in Natural Protected Areas". Journal of Heritage Tourism 13/1 (2016) 15-29.

Gümüşhane Valiliği. (1999). Cumuhuriyetin 75. yllında Gümüşhane. Gümüşhane 1999.

Gümüşhane Valiliği. (2016). Gümüşhane Kültür Envanteri. Gümüşhane 2016.

Günlü E., Pırnar İ. \& Yağcı K. (2009). "Preserving Cultural Heritage and Possible Impacts on Regional Development: Case of Izmir". International Journal of Emerging and Transition Economies 2/2 (2009) 213-229. Kaynak: 〈http://www.gumushane.gov.tr/cografi-konum>.

King N. \& Horrocks C. (2010). Interviews in Qualitative Research. Croydon 2010.

Lane B. (2009). "Thirty Years of Sustainable Tourism”. Eds. S. Gössling, M. C. Hall \& D. B. Weaver, Sustainable Tourism Futures: Perspectives on Systems, Restructuring and Innovations (2009). New York.

Lopez-Guzman T. \& Santa-Cruz F. G. (2017). "Visitors' Experiences with Intangible Cultural Heritage: A Case Study From Cordoba, Spain”. Journal of Heritage Tourism 12/4 (2017) 410-415.

Merriam S. B. (2015). Nitel Araştırma: Desen ve Uygulama İçin Bir Rehber. (Çev. S. Turan). Ankara 2015.

Mitsche N., Vogt F., Knox D., Cooper I., Lombardi P. \& Ciaffi D. (2013). "Intangibles: Enchancing Access to Cities' Cultural Heritage Through Interpretation". International Journal of Culture, Tourism and Hospitality Research 7/1 (2013) 68-77.

Oğuz M. Ö. (2013). "Terim Olarak Somut Olmayan Kültürel Miras”. Milli Folklor Dergisi 25/100 (2013) $5-13$.

Omar H. (2013). The Development of Sustainable Cultural Heritage Tourism in Malaysia: Implication for Planning and Management. Unpublished Doctoral Dissertation. Newcastle University. Newcastle 2013. 
Ott M., Dagnino F. M. \& Pozzi F. (2015). "Intangible Cultural Heritage: Towards Collaborative Planning of Educational Interventions". Computers in Human Behavior 51/B (2015) 1314-1319.

Ölçer-Özünel E. (2017). "İnsanlar, Gezegen ve Refah İçin Bir Eylem Planı: Somut Olmayan Kültürel Miras ve 2030 Sürdürülebilir Kalkınma Hedeflerine Eleştirel Yaklaşım”. Milli Folklor Dergisi 29/116 (2017) 18-32.

Özkan H. \& Yurttaş H. (2012). Tarih, Arkeoloji ve Sanat Tarihi Araştırmalart-II: Orta Çağ'dan Günümüze Gümüşhane. Gümüşhane 2012.

Patton M. Q. (1990). Qualitative Evaluation and Research Methods. Beverly Hills 1990. Kaynak: <http://legacy.oise.utoronto.ca/research/field-centres/ross/ctl1014/Patton1990.pdf〉.

Patton M. Q. (2014). Nitel Araştırma ve Değerlendirme Yöntemleri. (Çev. A. Çekiç \& A. Bakla). Ankara 2014.

Resmi Gazete. (2006). "Somut Olmayan Kültürel Mirasın Korunması Sözleşmesinin Onaylanmasının Uygun Bulunduğuna Dair Kanun”. <Kaynak: http://www.resmigazete.gov.tr/eskiler/2006/01/200601 21-1.htm>.

Severo M. \& Venturini T. (2016). "Intangible Cultural Heritage Webs: Comparing National Networks with Digital Methods". New Media and Society 18/8 (2016) 1616-1635.

Şanlı̈̈z-Özgen H. K., Dilek S. E., Türksoy S. S. \& Çelebi S. K. (2016). Sürdürülebilir Turizm Yönetimi. Ankara 2016.

Şencan H. (2005). Sosyal ve Davranışsal Ölçümlerde Güvenilirlik ve Geçerlilik. Ankara 2005.

T.C. Kültür ve Turizm Bakanlı̆̆ı (KTB). (2018). "Somut Olmayan Kültürel Mirasın Sözleşmesi Hakkında: Somut Olmayan Kültürel Miras”. Araşttrma ve Eğitim Genel Müdürlügü. Kaynak: <http://aregem. kulturturizm.gov.tr/TR,50837/somut-olmayan-kulturel-mirasin-korunmasi-sozlesmesi-hak-.html>.

Timothy D. J. (2014). “Contemporary Cultural Heritage and Tourism: Development Issues and Emerging Trends". Public Archeology 13/1-3 (2014) 30-47.

Türker A. \& Çelik İ. (2012). "Somut Olmayan Kültürel Miras Unsurlarının Turistik Ürün Olarak Geliştirilmesine Yönelik Alternatif Öneriler”. Yeni Fikir Dergisi 9 (2012) 86-98.

UNEP. \& UNWTO. (2005). Making Tourism More Sustainable: A Guide for Policy Makers.

UNESCO. (2007). "Safeguarding Intangible Heritage and Sustainable Cultural Tourism: Opportunities and Challenges". UNESCO-EIHAP Regional Meeting (2007) 1-137. Hué.

UNESCO. (2015). “What Is Intangible Cultural Heritage?”. Kaynak: <http://www.unesco.org/culture/ich/ index.php?lg=en\&pg=00002>.

UNESCO. (2018). Doğal ve Kültürel Miras. Kaynak: http://www.unesco.org.tr/Pages/126/123/UNESCO$\% \mathrm{C} 4 \% \mathrm{~B} 0 \mathrm{nsanl} \% \mathrm{C} 4 \% \mathrm{~B} 1 \% \mathrm{C} 4 \% 9 \mathrm{~F} \% \mathrm{C} 4 \% \mathrm{~B} 1 \mathrm{n}-$ Somut-Olmayan-K\%C3\%BClt\%C3\%BCrelMiras\%C4\%B1-Temsili-Listesi, Erişim Tarihi: 22 Aralık 2018.

Ülker T., Yılmaz N., Kazancı Ş. \& Doğru E. (2011). Gümüş̧hane Halk Kültürü-1-2-3-4-5-6. Trabzon 2011.

Yıldırım A. \& Şimşek H. (2016). Sosyal Bilimlerde Nitel Araştırma Yöntemleri. Ankara 2016.

Yurttaş H. (2008). "Gümüşhane/Kürtün'deki Kültür Varlıkları". Atatürk Üniversitesi Türkiyat Araștırmaları Enstitüsü Dergisi 15/38 (2008) 185-195. 